\title{
Nitrogen Rejection from Natural Gas by Dual Reflux-Pressure Swing Adsorption using Activated Carbon and Ionic Liquidic Zeolite
}

\author{
Roman Weh ${ }^{\text {a) }}$, Gongkui Xiao ${ }^{\text {a) }}$, Md Ashraful Islam ${ }^{\text {b) }}$, Eric F. May)* \\ ${ }^{a)} A R C$ Training Centre for LNG Futures, Fluid Science \& Resources Division, The University of Western \\ Australia, 35 Stirling Highway, Perth WA 6009, Australia \\ b)Oil \& Gas Treatment Division, Research \& Development Center, Saudi Aramco Oil Company, Dhahran \\ 31311, Saudi Arabia
}

*Corresponding author: eric.may@uwa.edu.au

\section{Abstract}

The separation of a natural gas mixture containing $85 \mathrm{~mol}^{\circ} \mathrm{CH}_{4}$ and $15 \mathrm{~mol} \% \mathrm{~N}_{2}$ by dual reflux-pressure swing adsorption (DR PSA) was investigated using dynamic non-isothermal numerical simulations previously benchmarked against experiments. Two different adsorbents were employed: a commercially available activated carbon (AC1) and the recently developed ionic liquidic zeolite (ILZ), which has about twice the selectivity for methane over nitrogen than the activated carbon. Four DR PSA cycle configurations (PL-A, PHA, PL-B and PH-B) were studied and iteratively optimized in terms of separation performance and energy consumption. The dynamic non-isothermal simulations, implemented in the software platform Aspen Adsorption, included a polytropic compressor model with temperature dependent heat capacities for more realistic predictions of the compressor duty. The heavy product to feed ratio, the feed step time and the light reflux ratio were selected as key optimization parameters for all four cycles at fixed bed pressure ratio, feed location and feed flow rate. The simulations showed that A-cycles were superior to B-cycles in terms of their separation performance for both adsorbent materials. Overall, the separation performance achieved by AC1 was lower than that by ILZ. At optimized conditions for AC1, PL-A and PH-A cycles achieved approximately 92 mol\% $\mathrm{CH}_{4}$ in the heavy product and $4.5 \mathrm{~mol} \% \mathrm{CH}_{4}$ in the light product with corresponding energy requirement at $9.9 \mathrm{~kJ} \mathrm{~mol}^{-1}$ (feed) and $8.7 \mathrm{~kJ} \mathrm{~mol}^{-1}$ (feed), while using the ILZ adsorbent, both PL-A and PH-A cycles were able to deliver 0.9 mol\% $\mathrm{CH}_{4}$ in the light product and 93.5 mol\% $\mathrm{CH}_{4}$ in the heavy product. The cycle work of the PL-A and PH-A configuration using ILZ was 8.8 and $7.7 \mathrm{~kJ} \mathrm{~mol}^{-1}$ (feed), respectively. These simulation results show that DR PSA processes using Ionic Liquidic Zeolites can meet strict natural gas separation requirements and that such processes can efficiently upgrade sub-quality natural gas.

Keywords: Nitrogen Rejection; Sub-quality Natural Gas; DR PSA; Methane Upgrading; Ionic Liquidic Zeolite 


\section{Introduction}

In 2017 , the world primary energy consumption grew by $2.2 \%$. This development was driven by natural gas consumption which has risen by 3.39 trillion cubic feet (tcf) since 2010 [1]. As the cleanest fossil fuel, the growing importance of natural gas in the global energy market means that the need for production from smallscale and sub-quality reservoirs is becoming increasingly important [2]. According to the Gas Technology Institute, sub-quality natural gas contains at least one of the following contaminants in excess: $\geq 2 \mathrm{~mol} \% \mathrm{CO}_{2}$, $\geq 4$ mol\% $\mathrm{N}_{2}$ and $\geq 4$ ppmv $\mathrm{H}_{2} \mathrm{~S}$. High concentrations of $\mathrm{CO}_{2}$ and $\mathrm{N}_{2}$ reduce the heating value of the gas and may cause other technical problems and are thus removed to meet pipeline and transport specifications [3]. The nitrogen content in pipelines is usually limited to $4 \mathrm{~mol} \%$ to $7 \mathrm{~mol} \%$, depending on local regulations [4]. For LNG, the product specifications are even stricter and the $\mathrm{N}_{2}$ content must be below 1 mol\% due to the risk of sloshing and rollover during transport and storage $[5,6]$.

The separation of $\mathrm{N}_{2}$ and $\mathrm{CH}_{4}$ is especially challenging due to their molecular similarities. Industrial nitrogen rejection units (NRU) are mostly based on cryogenic distillation [2]; however, while such processes often achieve high $\mathrm{CH}_{4}$ recovery and purity ( $\geq 98 \mathrm{~mol} \%$ ), cryogenic distillation is usually only economically viable at large gas flow rates (> $25 \mathrm{MMscfd}$ ) [7]. At smaller scales (particularly < $15 \mathrm{MMscfd}$ ) pressure swing adsorption (PSA) has been used as an alternative technology for $\mathrm{N}_{2}$ rejection, especially for achieving pipeline $\mathrm{CH}_{4}$ specifications [2]. However, the rejected $\mathrm{N}_{2}$ product stream produced by a conventional PSA process usually contains a considerable amount of $\mathrm{CH}_{4}\left(>1 \mathrm{~mol} \% \mathrm{CH}_{4}\right)$ that cannot be vented to the atmosphere because of emission regulations $[2,8]$, and the only use of such a stream is for power generation, which is not always desirable. To overcome such limitations, Dual Reflux Pressure Swing Adsorption (DR PSA) processes offer the possibility of simultaneously enriching $\mathrm{CH}_{4}$ to pipeline specifications and also preventing $\mathrm{CH}_{4}$ loss to the $\mathrm{N}_{2}$ vent stream, thus helping to meet emission regulations. This is achievable because DR PSA processes are in principle capable of producing two high-purity products from a binary feed mixture in a single step, i.e. one product enriched with the highly adsorbed component (denoted as A) and one product enriched with the less adsorbed component (denoted as B). In the open literature, the first DR PSA process demonstrated experimentally was reported by Diagne et al. $[9,10]$ for the separation of a $20 \mathrm{~mol} \% \mathrm{CO}_{2}+80 \mathrm{~mol} \% \mathrm{~N}_{2}$ mixture. They achieved a separation with the light product containing $<4 \mathrm{~mol} \% \mathrm{CO}_{2}$ and the heavy product containing 94 mol\% $\mathrm{CO}_{2}$ by partially refluxing both heavy $\left(\mathrm{CO}_{2}\right.$ rich) and light $\left(\mathrm{N}_{2}\right.$ rich) product streams. This separation performance exceeded that reached by conventional PSA cycles and showcased that two purified product streams with high recoveries were in fact achievable as the DR PSA cycle combines both stripping and enriching operations in one adsorption bed. 
Kearns et al. [11] identified four basic DR PSA cycle configurations: feed to the high- (PH) or low-pressure (PL) bed and pressure reversal with the heavy (A) or light (B) component. These options lead to the four basic cycle configurations PH-A, PL-A, PH-B and PL-B, which are shown schematically in Figure 1.
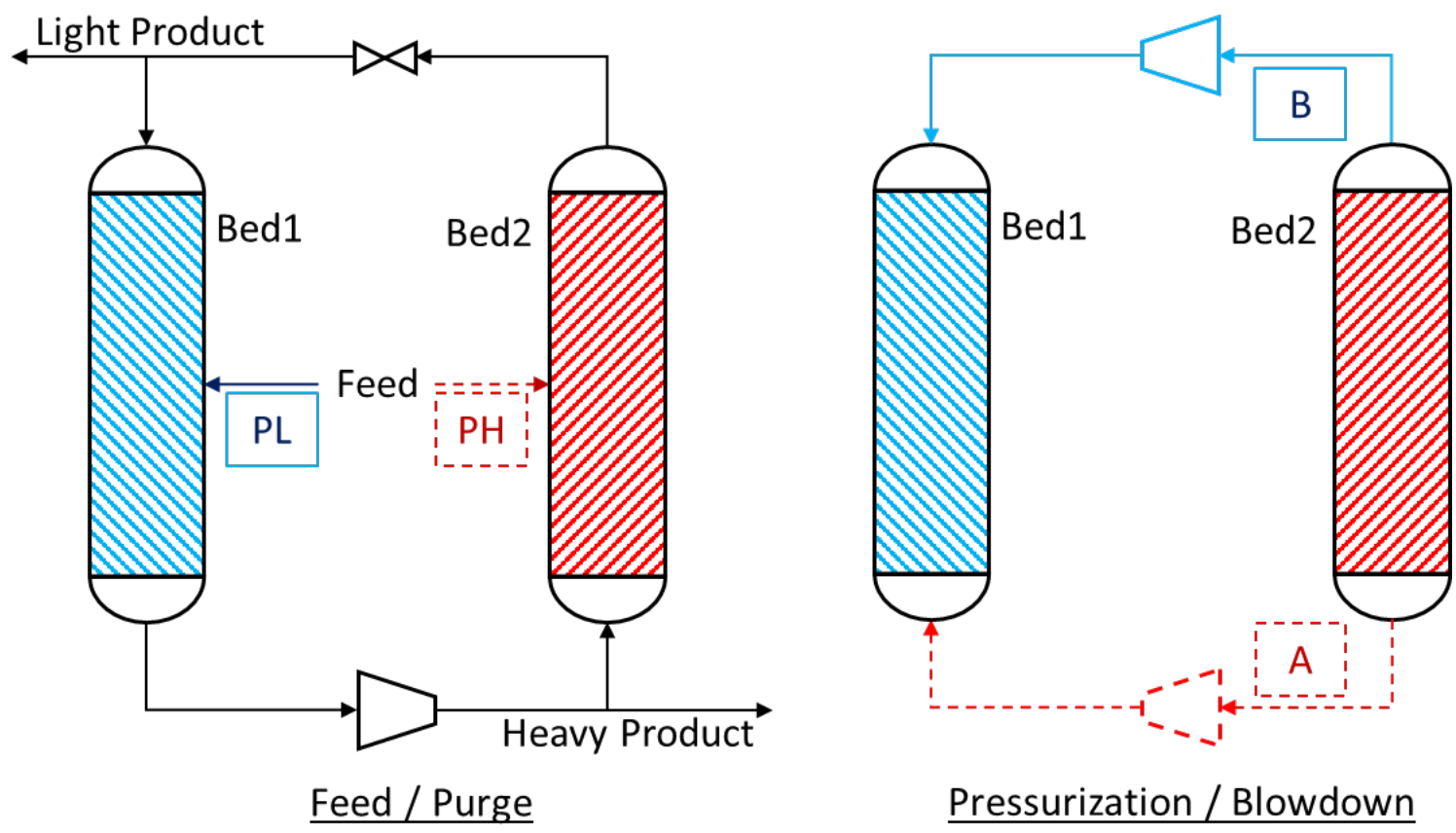

Figure 1. Half cycle (feed/purge step and pressurization/blowdown step) for each of the four basic DR PSA configurations: feed to the high-pressure $(\mathrm{PH})$ or low-pressure $(\mathrm{PL})$ bed and pressure reversal with the heavy (A) or light (B) adsorbate.

Simulations of DR PSA cycles reported in the literature range from highly simplified analytical models to rigorous numerical models considering coupled energy and material balance equations. Analytical models provided important insights into DR PSA operational parameters and process performance [11-17]. However, the need to apply several simplifying assumptions, such as isothermal behaviour and perfect separation, limit their application. Bhatt et al. $[18,19]$ developed an isothermal model in Aspen Adsorption to describe DR PSA experiments they conducted with a 5 mol\% $\mathrm{CH}_{4}+95 \mathrm{~mol} \% \mathrm{~N}_{2}$ feed, which achieved $1.5 \mathrm{~mol} \% \mathrm{CH}_{4}$ in the light product and 55 mol\% $\mathrm{CH}_{4}$ in the heavy product. Their numerical model predicted product compositions deviating by between $(-2$ and +8$)$ mol\% from the experimental results. Their model was also benchmarked against experimental data from McIntyre et al. [20, 21], who demonstrated the separation of dilute ethane from a $\mathrm{N}_{2}$ vent stream. Both light and heavy product compositions could be reasonably predicted by the isothermal model given the low adsorbate concentrations. However, as discussed by Zhang et al. [22], isothermal models may prove unrealistic for scenarios where the adsorbate fraction is high and thermal effects should not be ignored.

Zhang et al. [23] developed a non-isothermal dynamic numerical simulation of $\mathrm{CH}_{4}$ and $\mathrm{N}_{2}$ separations by DR PSA implemented in Aspen Adsorption. The model was benchmarked against experimental data from Saleman 
et al. [24] and the root mean square deviations of the $\mathrm{CH}_{4}$ concentrations in the light and heavy products were ( 0.3 and 2.4$)$ mol\%, respectively. The impact of reflux rates, feed step time, dispersion as well as mass transfer coefficients was investigated. Numerical dispersion was also considered as a source of uncertainty. Subsequently, Zou et al. [25] reported a non-isothermal DR PSA model that employs two different pressure control schemes, and was thus able to model cycles with a continuously changing or constant bed pressure during feed / purge step. The model was compared to the experimental results of both Mclntyre et al. [20, 21] (continuously changing pressure profile) and Saleman et al. [24] (constant pressure profile), in which the binary mixtures $\mathrm{C}_{2} \mathrm{H}_{6}+\mathrm{N}_{2}$ and $\mathrm{CH}_{4}+\mathrm{N}_{2}$ were separated, respectively. The mean deviation between the modelling results and the experiments for the $\mathrm{CH}_{4}+\mathrm{N}_{2}$ separation was found to be $(0.04$ and 0.2$)$ mol\% for $\mathrm{CH}_{4}$ and $\mathrm{N}_{2}$ in the heavy and light product, respectively. Overall, these results demonstrate that rigorous non-isothermal numerical simulations of DR PSA cycles are capable of predicting experimental results with better fidelity than more simplified models and can be used effectively for optimization purposes.

In this work, we report the separation of an 85 mol\% $\mathrm{CH}_{4}+15$ mol\% $\mathrm{N}_{2}$ gas mixture by DR PSA using the nonisothermal numerical simulations implemented within Aspen Adsorption software that we have described previously $[8,23,25,26]$. In particular, we examine the impact of adsorbent selectivity on the separation performance achieved with the four DR PSA configurations (PL-A, PH-A, PL-B, PH-B) by running the simulations with two different methane-selective adsorbents: (i) the Activated Carbon characterized by Rufford et al. [27], referred to here as AC1, and (ii) the recently developed novel ionic liquidic zeolite (ILZ) [8]. The influence of heavy reflux to feed ratio, light reflux flow rate and feed step time on the separation performance and energy requirements is also presented, together with the results of an iterative approach used to optimize product purities and compressor duty.

\section{Simulation Details}

\subsection{Adsorption Isotherm Parameters}

The properties of the activated carbon AC1 considered in this work were previously reported by Rufford et al. [27]. The adsorption isotherms of pure $\mathrm{CH}_{4}$ and $\mathrm{N}_{2}$ on $\mathrm{AC} 1$ were represented by the Langmuir isotherm equation (Eq. 1) with the same parameter values as reported by Zhang et al. [23]. The ionic liquidic zeolite (ILZ) is a patented novel adsorbent available in industrial-scale quantities from Gas Capture Technologies Pty Ltd [28] that exhibits higher $\mathrm{CH}_{4} / \mathrm{N}_{2}$ selectivity than commercial adsorbents, as discussed below [8]. The isotherm parameters for $\mathrm{CH}_{4}$ and $\mathrm{N}_{2}$ adsorption on ILZ were obtained by regressing the single-component isotherm data disclosed by Li et al. [8] using the Langmuir equation. To account for the competitive adsorption of $\mathrm{CH}_{4}$ and $\mathrm{N}_{2}$ in gas mixtures, the single component isotherm parameters were used in the extended Langmuir model (Eq 2) for both adsorbents.

$$
Q=\frac{I P_{1, i} \cdot \exp \left(I P_{2, i} / T\right) \cdot p}{1+I P_{3, i} \cdot \exp \left(I P_{4, i} / T\right) \cdot p}
$$




$$
Q_{i}=\frac{I P_{1, i} \cdot \exp \left(I P_{2, i} / T\right) \cdot p_{i}}{1+\sum_{k}\left(I P_{3, k} \cdot \exp \left(I P_{4, i} / T\right) \cdot p_{k}\right)}
$$

Equation 2

Here $Q$ is the equilibrium adsorption capacity for a pure gas; $I P_{1, i}$ to $I P_{4, i}$ are isotherm parameters obtained from single component isotherm; $T$ is the adsorbent temperature, $p$ is the gas pressure; $Q_{i}$ is the component equilibrium adsorption capacity (either $\mathrm{CH}_{4}$ or $\mathrm{N}_{2}$ ) in a gas mixture, $p_{i}$ is the partial pressure of a component in the gas mixture, and the subscript $k$ has the same meaning as $i$ but is used to distinguish between $\mathrm{CH}_{4}$ and $\mathrm{N}_{2}$ in the summation operator. The isotherm parameters $I P_{1, i}$ to $I P_{4, i}$ are listed in Table 1.

Table 1. $\mathrm{CH}_{4}$ and $\mathrm{N}_{2}$ isotherm parameters for $\mathrm{AC1}$ and ILZ.

\begin{tabular}{cccc}
\hline Parameter & Component $i$ & $\mathrm{AC} 1$ & $\mathrm{ILZ}$ \\
\hline \multirow{2}{*}{$\mathbb{P}_{1, i}\left[\mathrm{kmol} \mathrm{kg}^{-1} \mathrm{bar}^{-1}\right]$} & $\mathrm{CH}_{4}$ & $6.58 \mathrm{E}-07$ & $1.15 \mathrm{E}-07$ \\
& $\mathrm{~N}_{2}$ & $7.30 \mathrm{E}-07$ & $1.27 \mathrm{E}-07$ \\
$\mathbb{I P}_{2, i}[\mathrm{~K}]$ & $\mathrm{CH}_{4}$ & $2.08 \mathrm{E}+03$ & $2.53 \mathrm{E}+03$ \\
& $\mathrm{~N}_{2}$ & $1.72 \mathrm{E}+03$ & $1.99 \mathrm{E}+03$ \\
\multirow{2}{*}{$P_{3, i}\left[\mathrm{bar}^{-1}\right]$} & $\mathrm{CH}_{4}$ & $1.19 \mathrm{E}-04$ & $3.44 \mathrm{E}-05$ \\
& $\mathrm{~N}_{2}$ & $1.75 \mathrm{E}-04$ & $4.45 \mathrm{E}-05$ \\
& $\mathrm{CH}_{4}$ & $2.08 \mathrm{E}+03$ & $2.53 \mathrm{E}+03$ \\
& $\mathrm{~N}_{2, i}[\mathrm{~K}]$ & $1.72 \mathrm{E}+03$ & $1.99 \mathrm{E}+03$ \\
\hline
\end{tabular}

Figure 2 shows the single-component isotherms of $\mathrm{CH}_{4}$ and $\mathrm{N}_{2}$ on $\mathrm{AC} 1$ and ILZ calculated using the isotherm parameters for a comparison of these two materials. It is clear that AC1 has a higher capacity for both $\mathrm{CH}_{4}$ and $\mathrm{N}_{2}$ than the ILZ does. However, the ILZ has a much higher $\mathrm{CH}_{4} / \mathrm{N}_{2}$ selectivity (calculated here simply as the ratio between the amounts of $\mathrm{CH}_{4}$ and $\mathrm{N}_{2}$ adsorbed at 1 bar and $30{ }^{\circ} \mathrm{C}$ using their respective pure gas isotherms) than that for AC1 because of its low capacity for $\mathrm{N}_{2}$. The $\mathrm{CH}_{4}$ over $\mathrm{N}_{2}$ selectivity of ILZ is 4.8 at 1 bar and $30^{\circ} \mathrm{C}$ whereas the selectivity of $\mathrm{AC} 1$ is only 2.8 at the same condition.

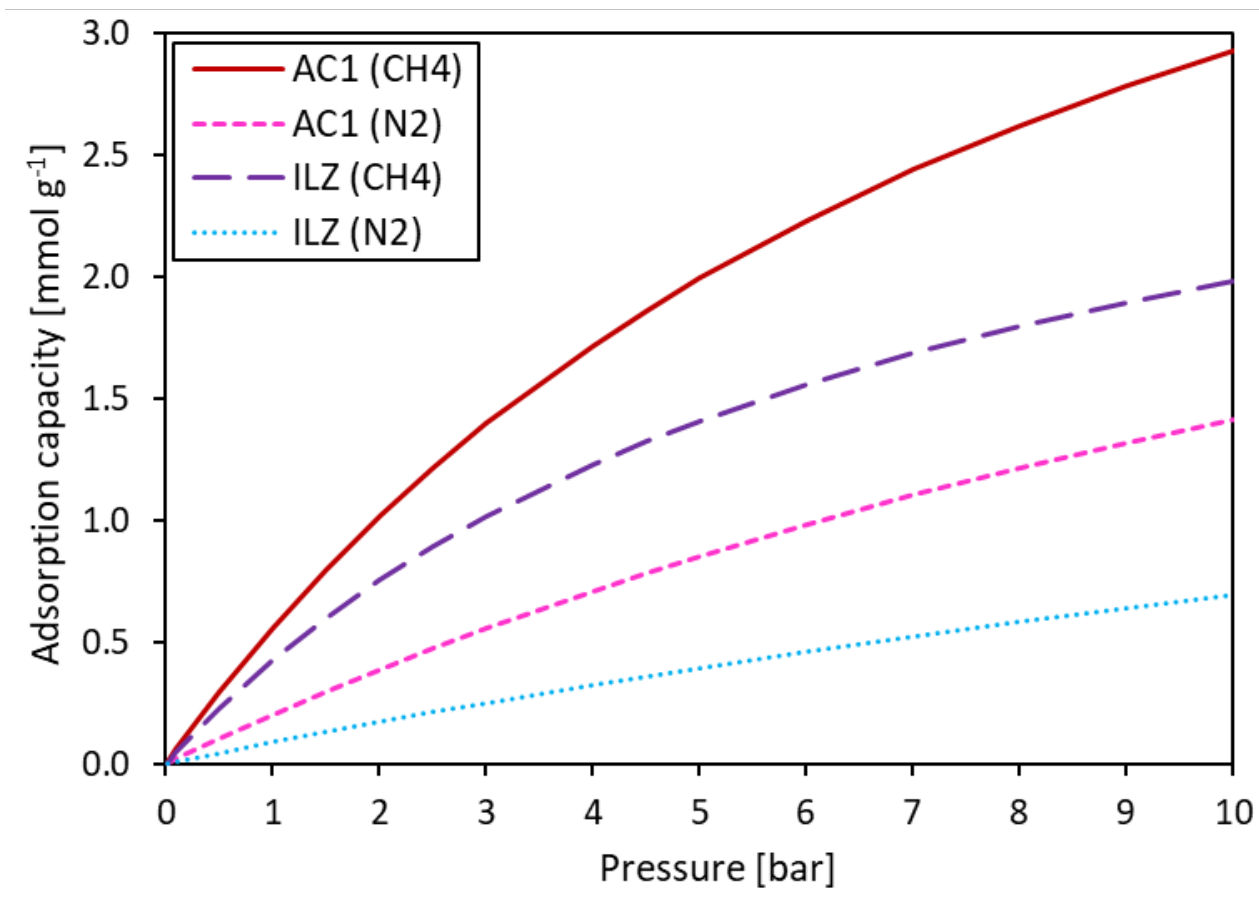

Figure 2. Single-component isotherms for $\mathrm{CH}_{4}$ and $\mathrm{N}_{2}$ on $\mathrm{ACl}$ and ILZ at $30^{\circ} \mathrm{C}$. 


\subsection{Pressure Flow Network}

The DR PSA pressure flow network used in the numerical simulations is depicted in Figure 3. Each of the two identical columns is modelled by two separate (half) adsorption beds, allowing the feed inlet stream to enter the adsorption bed at an intermediate position. Gas rich in the heavy (more adsorbed) component is partially transferred from the bottom of the low-pressure column to the high-pressure column as a reflux stream. A compressor (Comp_bot) located after the bottom of this low-pressure column is used to achieve the pressure required for this reflux stream to enter the other column. This compressor is controlled by a proportionalintegral-derivative (PID) controller (C1), which varies the volumetric discharge flow to maintain the specified pressure during the feed and purge step. A heavy product surge tank $\left(T_{-} H\right)$ is used to mitigate pressure and composition fluctuations. A mass flow controller (MFC_HP) sets the heavy product flow rate while the remaining gas is refluxed. On the top of the columns, gas enriched in the light component is partially refluxed from the high-pressure column to the low-pressure column. A back pressure regulator (BPR1) maintains the high pressure of the corresponding column by a controller (C2) that adjusts the valve flow coefficient. A light product tank ( $T_{-} L_{\text {) }}$ is used to buffer the pressure and compositions of the top product. A mass flow controller (MFC_LR) controls the light reflux rate and light product is drawn through BPR2. A top compressor is employed to conduct the pressurization / blowdown steps that utilize the light gas (B-cycles). This compressor is only used in B-cycles and can be bypassed by closing valves TB3 and TB4 in A-cycles when it is not needed. 


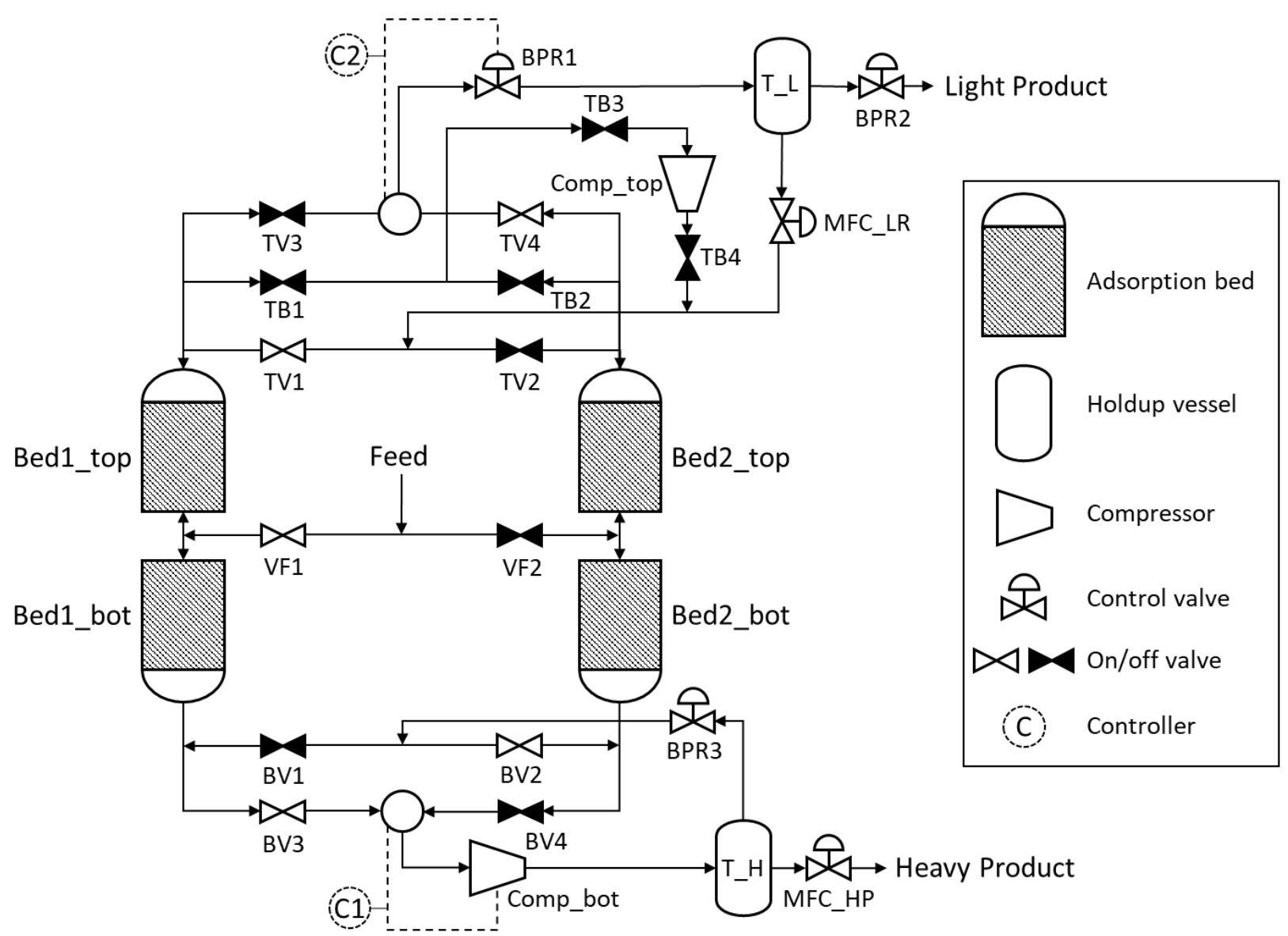

Figure 3. Process flow diagram of the DR PSA model during feed/purge step (PL-A cycle). Black shaded valves indicate that they are closed whereas white shaded valves are open.

In our previous work [8, 23, 25, 26], UDS1 (Upwind Differencing Scheme 1) and Quadratic Upwind Differencing Scheme (QDS) discretisation methods were used to solve the partial differential equations in the DR PSA model. UDS1 is a first order differencing scheme based on a first-order Taylor expansion, and QDS is based on quadratic interpolation, in contrast to the linear interpolation typical of many other schemes. Both of these two methods produced reliable and stable simulations in our previous work. However, neither of them could produce a stable simulation in this work when the transient gas purity in the column approached 100 mol\% (the upper purity variable bound), which often resulted in a failure of the solver and a crash of the simulation. Instead, the MIXED discretization method was adopted in this work to handle such numerical fluctuations. To increase simulation accuracy, the number of discretisation nodes was increased from 20 (as used by Zhang et al. [23]) to 40 per half-bed for all simulations. This doubling of nodes increased the computational time and approximately 3 to 10 hours were required to reach cyclic steady state (CSS) conditions on a multi-core machine with an Intel i7 chip running at $2.7 \mathrm{GHz}$ with $8 \mathrm{~GB}$ RAM; the time required strongly depended on the imposed parameters. CSS was deemed to have been reached when the relative change in the total loading and solid temperature between two consecutive cycles was $\leq 10^{-5}$. At CSS, the average overall mass balance error present in the simulation were $-0.38 \%$ and $-0.55 \%$ for AC1 and ILZ, respectively, whereas the average 
$\mathrm{CH}_{4}$ component balance errors were $1.5 \%$ and $2.6 \%$. The simulation parameters, summarized in Table 2, were taken from Zhang et al. [23] for AC1 and from Li et al. [8] for ILZ.

Table 2. Adsorption bed modelling parameters used in this work.

\begin{tabular}{|c|c|c|}
\hline \multirow{2}{*}{$\begin{array}{l}\text { Parameter } \\
\text { Column parameters }\end{array}$} & \multicolumn{2}{|l|}{ Value } \\
\hline & \multirow{2}{*}{\multicolumn{2}{|c|}{$0.98 \mathrm{~m}$}} \\
\hline$\overline{\text { Total bed length }}$ & & \\
\hline Axial feed position $\left(z_{F}\right)$ & \multicolumn{2}{|l|}{0.5} \\
\hline Column internal diameter & \multicolumn{2}{|l|}{$0.035 \mathrm{~m}$} \\
\hline Column wall thickness & \multicolumn{2}{|l|}{$0.0016 \mathrm{~m}$} \\
\hline $\begin{array}{l}\text { Heat transfer coefficient between } \\
\text { column wall and ambient }\end{array}$ & \multicolumn{2}{|l|}{$10 \mathrm{~W} \mathrm{~m}^{-2} \mathrm{~K}^{-1}$} \\
\hline Wall thermal conductivity & \multirow{2}{*}{\multicolumn{2}{|c|}{$\begin{array}{l}16 \mathrm{~W} \mathrm{~m}^{-1} \mathrm{~K}^{-1} \\
500 \mathrm{~J} \mathrm{~kg}^{-1} \mathrm{~K}^{-1}\end{array}$}} \\
\hline Wall specific heat capacity & & \\
\hline Adsorbent parameters & $\mathrm{AC1}$ & ILZ \\
\hline Inter-particle voidage & 0.42 & 0.62 \\
\hline Intra-particle voidage & 0.65 & 0.37 \\
\hline Bulk density & $435 \mathrm{~kg} \mathrm{~m}^{-3}$ & $700 \mathrm{~kg} \mathrm{~m}^{-3}$ \\
\hline Adsorbent particle radius & $0.0015 \mathrm{~m}$ & $0.0015 \mathrm{~m}$ \\
\hline Adsorbent shape factor & 0.752 & 0.752 \\
\hline Adsorbent specific heat capacity & $1000 \mathrm{~J} \mathrm{~kg}^{-1} \mathrm{~K}^{-1}$ & $960 \mathrm{~J} \mathrm{~kg}^{-1} \mathrm{~K}^{-1}$ \\
\hline Adsorbent heat conductivity & $0.8 \mathrm{~W} \mathrm{~m}^{-1} \mathrm{~K}^{-1}$ & $0.8 \mathrm{~W} \mathrm{~m}^{-1} \mathrm{~K}^{-1}$ \\
\hline Mass transfer coefficient & AC1 & ILZ \\
\hline $\mathrm{N}_{2}$ mass transfer coefficient & $3 s^{-1}$ & $10 \mathrm{~s}^{-1}$ \\
\hline $\mathrm{CH}_{4}$ mass transfer coefficient & $1 \mathrm{~s}^{-1}$ & $5 s^{-1}$ \\
\hline \multicolumn{3}{|l|}{ Others } \\
\hline $\mathrm{N}_{2}$ heat capacity & \multirow{2}{*}{\multicolumn{2}{|c|}{$\begin{array}{l}29 \mathrm{~kJ} \mathrm{kmol}^{-1} \mathrm{~K}^{-1} \\
35 \mathrm{~kJ} \mathrm{kmol}^{-1} \mathrm{~K}^{-1}\end{array}$}} \\
\hline $\mathrm{CH}_{4}$ heat capacity & & \\
\hline Gas phase heat conductivity & \multicolumn{2}{|l|}{$0.16 \mathrm{~W} \mathrm{~m}^{-1} \mathrm{~K}^{-1}$} \\
\hline
\end{tabular}

\subsection{Compressor Model}

Determination of the compressor work $W$ is essential to estimate the energy requirements of the process and therefore its operational costs. In contrast to previous publications [8, 23, 25], a polytropic compressor model was implemented in this work using the Aspen Custom Modeler language within Aspen Adsorption to calculate the compression work more realistically; furthermore the compressor was operated in a constant volumetric flow mode during the pressurization/blowdown step and in a varying flow rate mode during the feed/purge step via a PID controller. The compressor model equations are summarized in Table 3. Temperature dependent heat capacities $C_{P}$ for both $\mathrm{CH}_{4}$ and $\mathrm{N}_{2}$ were used with constants $a_{j, i}$ sourced from literature [29] as shown in Table 4. 
Table 3. Polytropic compression model equations to calculate the compressor duty $W$.

\begin{tabular}{clc}
\hline Description & \multicolumn{1}{c}{ Equation } & Equation No \\
\hline Outlet temperature, $T_{2}$ & $T_{2}=T_{1}\left(P_{1} / P_{2}\right)^{\frac{1-k}{k}}$ & 3 \\
Average temperature, $T_{m}$ & $T_{m}=\left(T_{2}+T_{1}\right) / 2$ & 4 \\
Component molar heat capacity, $C_{p, i}$ & $C_{p, i}=\sum_{j=0}^{3} a_{j, i}\left(T_{m}\right)^{j}$ & 5 \\
Mixture molar heat capacity, $C_{p, m i x}$ & $C_{p, m i x}=\sum_{i} x_{i} C_{p, i}$ & 6 \\
Isentropic factor, $k$ & $k=\left(C_{p, m i x} /\left(C_{p, m i x}-R\right)\right)$ & 7 \\
Polytropic exponent, $n$ & $n /(n-1)=(k /(k-1)) \eta_{c}$ & 8 \\
Compression ratio, $R_{\mathrm{p}}$ & $R_{p}=N \sqrt{P_{2} / P_{1}}$ & 9 \\
Compressor duty, $W$ & $W=N \vartheta R T_{1}(k /(k-1))\left[R_{p}{ }^{n /(n-1)}-1\right]$ & 10 \\
\hline
\end{tabular}

Table 4. Constants $a_{j, i}$ for $C_{p, i}$ calculations (see Eq. 5 and Eq. 6).

\begin{tabular}{lllll}
\hline Component & $a_{0}$ & $a_{1}$ & $a_{2}$ & $a_{3}$ \\
\hline $\mathrm{CH}_{4}$ & $3.43 \times 10^{-2}$ & $5.47 \times 10^{-5}$ & $3.66 \times 10^{-9}$ & $-1.10 \times 10^{-11}$ \\
$\mathrm{~N}_{2}$ & $2.90 \times 10^{-2}$ & $2.20 \times 10^{-6}$ & $5.72 \times 10^{-9}$ & $-2.87 \times 10^{-12}$ \\
\hline
\end{tabular}

\section{Results and Discussion}

\subsection{Optimization Approach}

The aim of this work was to separate an $85 \mathrm{~mol} \% \mathrm{CH}_{4}+15 \mathrm{~mol} \% \mathrm{~N}_{2}$ model natural gas mixture into two product streams: one with more than 99 mol\% $\mathrm{N}_{2}$ to maximize the $\mathrm{CH}_{4}$ recovery and reduce any $\mathrm{CH}_{4}$ emissions, and the other with more than $93 \mathrm{~mol} \% \mathrm{CH}_{4}$ to meet a regional pipeline specification. An iterative optimization approach suggested by May et al. [8] was applied in this work, and the workflow of the strategy is shown in Figure 4 . The initial operating parameters such as heavy product to feed ratio $H / F$, feed step time $t_{F}$ and light reflux flow rate $R_{L}$ were chosen conservatively and varied in increments. Iteration steps were conducted to achieve (i) product purities meeting the objectives, (ii) maximized bed productivity and (iii) minimized cycle work. Typically, five iterations were required for convergence. 


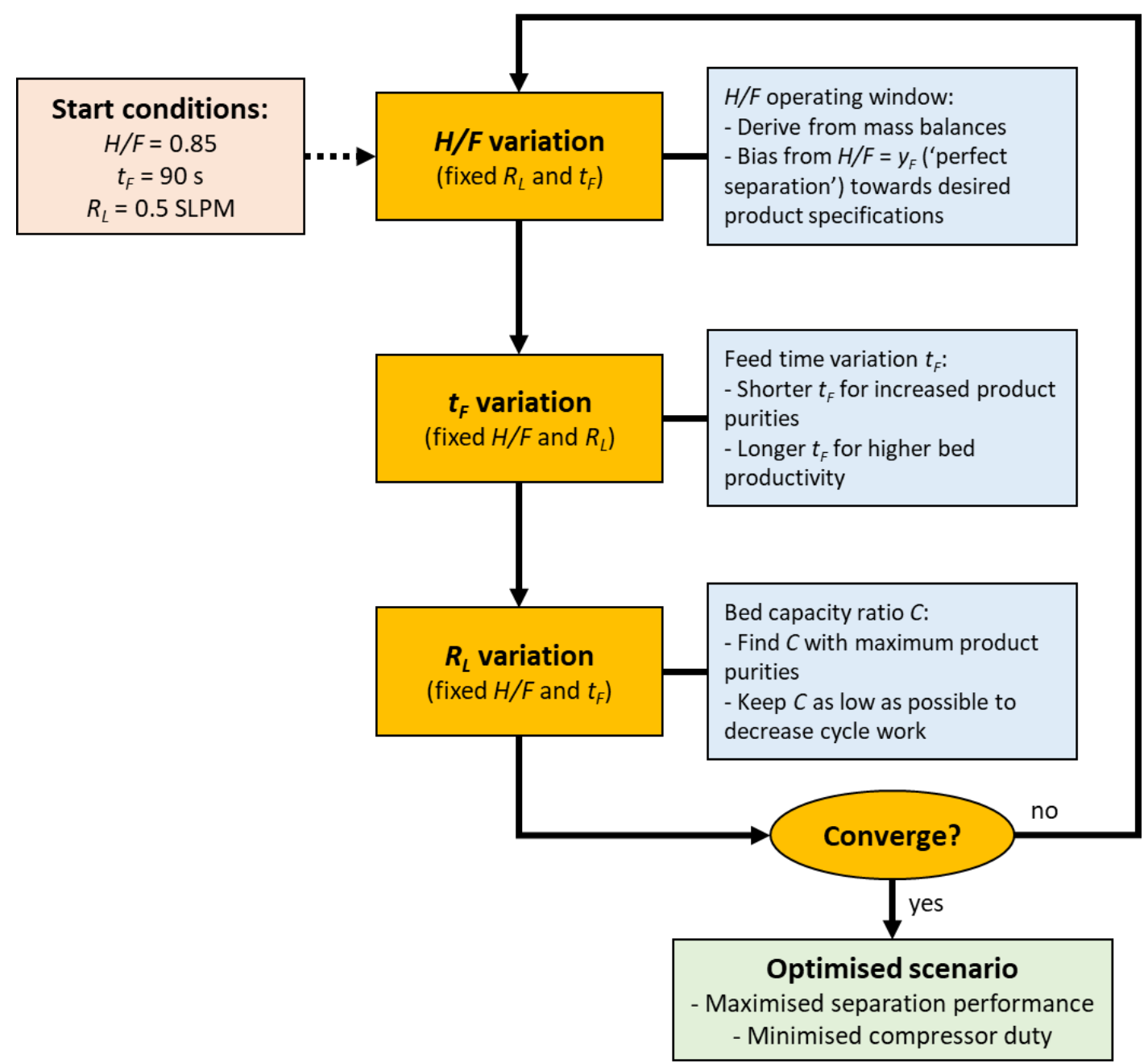

Figure 4. Graphical workflow of the iterative optimization approach suggested by May et al. [8].

The pressure ratio of high- and low-pressure bed, the feed flow rate and the ambient temperature were kept constant and are listed in Table 5.

Table 5. DR PSA operating conditions kept constant in this work.

\begin{tabular}{cc}
\hline Parameter & Value \\
\hline Low pressure $[\mathrm{bar}]$ & 1.0 \\
High pressure $[\mathrm{bar}]$ & 5.0 \\
Temperature $\left[{ }^{\circ} \mathrm{C}\right]$ & 25 \\
Feed flow rate $[\mathrm{SLPM}]$ & 1.25 \\
\hline
\end{tabular}

\subsection{Heavy Product to Feed Ratio Analysis}

To achieve 99 mol\% $\mathrm{N}_{2}$ in the light product and $93 \mathrm{~mol} \% \mathrm{CH}_{4}$ in the heavy product from a feed mixture of 85 mol\% $\mathrm{CH}_{4}+15$ mol\% $\mathrm{N}_{2}$, the heavy product to feed ratio $\mathrm{H} / \mathrm{F}$ needs to be within a narrow window between 0.848 and 0.914 , based on material balance constraints. Figure 5 shows the theoretical separation boundaries and the $\mathrm{CH}_{4}$ mole fraction in the heavy $\left(y_{H}\right)$ and light $\left(y_{L}\right)$ products as a function of the $H / F$ ratio for the four DR PSA configurations using adsorbent AC1 (solid symbols) and ILZ (hollow symbols). 

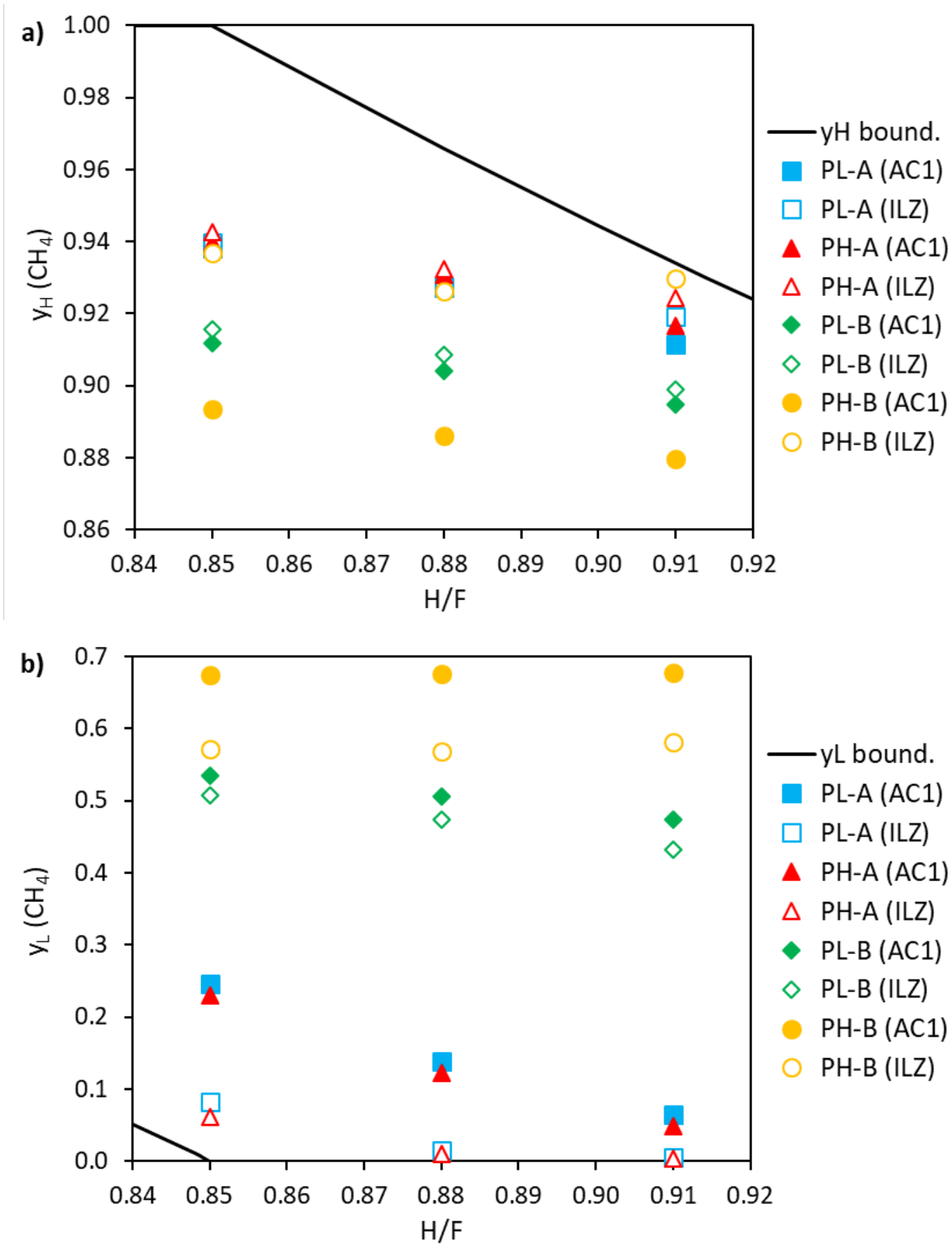

Figure 5. Influence of $H / F$ on the a) heavy $\left(y_{H}\right)$ and b) light product $\left(y_{L}\right)$ methane fractions for all four cycles (PL-A, PH-A, PL-B, PH-B) using AC1 (solid symbols) and ILZ (hollow symbols) at $t_{F}=90 \mathrm{~s}$ and $R_{L}=1.5 \mathrm{SLPM}$.

Figure 5a displays a decreasing trend of $y_{H}$ with an increase in $H / F$ for both adsorbents, as expected from the separation boundary based on material balance constraints. In general, there is no clearly distinguishable difference in $y_{H}$ for " $A$ " cycles between the two adsorbents, but the ILZ produced a higher $y_{H}$ than the AC1 did in the "B" cycles. The $y_{H}$ values for PL-B configuration using ILZ are higher than that achieved using AC1 by about 0.005 , while for the PH-B configuration the $y_{H}$ values for ILZ are about 0.045 higher than those for AC1. The targeted $y_{H}\left(>93 \mathrm{~mol}_{\mathrm{C}} \mathrm{CH}_{4}\right)$ could be achieved at $H / F=0.85$ by PL-A, PH-A and PH-B cycles using ILZ and by PL-A and PH-A cycles using AC1. 
Figure $5 b$ displays a decreasing trend of $y_{L}$ with the increase in $H / F$ for all the configurations except for the PHB cycles, which appear to be constant for both adsorbents. In contrast to the $y_{H}$ results, the $y_{L}$ values are more distinguishable between the two adsorbents. In terms of the $\mathrm{CH}_{4}$ loss in the light product, the ILZ adsorbent performs better than the AC1 adsorbent for the same DR PSA configurations, with the " $\mathrm{A}$ " cycles achieving a lower $\mathrm{CH}_{4}$ mole fraction in the light product than the "B" cycles for both of the adsorbents. The PH-A cycle with ILZ reached the light product separation target of $<1 \mathrm{~mol} \% \mathrm{CH}_{4}$ at $H / F=0.88$, while none of the cycles for $\mathrm{AC} 1$ approached the target of $1 \mathrm{~mol} \% \mathrm{CH}_{4}$ in the light product.

The superior performance of ILZ compared to AC1 is mainly attributed to the increased packing density and $\mathrm{CH}_{4} / \mathrm{N}_{2}$ selectivity of the ILZ. The inferior performance of the B-configurations is due to the differences between the pressure reversal step in A and B cycles. In B-cycles, the light component is used for pressure transfer (pressurization and blowdown). Although this will push back the adsorption front's location in the low-pressure bed, the light component $\mathrm{N}_{2}$ will be poorly adsorbed and not be able to replace the heavily adsorbed $\mathrm{CH}_{4}$. In addition, entrained $\mathrm{CH}_{4}$ from the high-pressure bed will further dilute the $\mathrm{N}_{2}$ composition profile in the upper part of both columns. In contrast, A-cycles use the heavy component for pressure transfer; as $\mathrm{CH}_{4}$ enters at the bottom of the column during pressure transfer, it will further adsorb in the lower part of the bed and drive any $N_{2}$ present out into the upper section. This leads to the column having a sharp adsorption front and a better separation performance.

\subsection{Feed Step Time and Productivity}

Another important parameter that influences the separation performance is the feed time, $t_{F}$. The effect of the feed time (varied from $45 \mathrm{~s}$ to $120 \mathrm{~s}$ ) on the separation is shown in Figure 6 at a constant light reflux rate 1.5 SLPM and an $H / F$ ratio of 0.91 and 0.88 for $A C 1$ and ILZ, respectively. Figure $6 a$ shows that reducing $t_{F}$ from $120 \mathrm{~s}$ to $45 \mathrm{~s}$ increased the $y_{H}$ by 0.01 to 0.03 for all the configurations performed on ILZ and for " $\mathrm{B}$ " configurations with $A C 1$. The "A" cycles with $A C 1$ exhibited a slight maximum for $y_{H}$ at a feed time of $60 \mathrm{~s}$. As a whole, each of the configurations using ILZ achieved higher $y_{H}$ than the corresponding cases using AC1. Using ILZ, the " $A$ " and " $B$ " configurations could produce heavy products with $y_{H}$ exceeding the target at a feed time of $90 \mathrm{~s}$ and $45 \mathrm{~s}$, respectively. None of the configurations using $\mathrm{AC} 1$ could meet the heavy product $\mathrm{CH}_{4}$ mole fraction specification. In the meantime for the $y_{L}$ in the light product as shown in Figure $6 \mathrm{~b}$, only " $\mathrm{A}$ " configurations using ILZ could attain the objective of limiting $y_{L}$ to less than $1 \mathrm{~mol} \%$, and none of other combinations could meet the target. Figure $6 \mathrm{~b}$ also shows that both adsorbents had a slight minimum in $y_{\llcorner}$at $t_{F}=60 \mathrm{~s}$ but with very small differences to the values obtained at $45 \mathrm{~s}$ or $75 \mathrm{~s}$. This indicates that there is a plateau where $y_{L}$ is not strongly affected by varying $t_{F}$ in contrast to $t_{F}=120 \mathrm{~s}$, where the amount of $\mathrm{CH}_{4}$ in the 
light product increases by up to $15 \mathrm{~mol} \% \mathrm{CH}_{4}$ due to breakthrough from the bed. Therefore, the feed step time can be varied between $45 \mathrm{~s}$ and $75 \mathrm{~s}$ and biased towards higher values for increased productivity, while ensuring the target light product composition $\left(1 \mathrm{~mol}_{\mathrm{C}} \mathrm{CH}_{4}\right)$ is met.
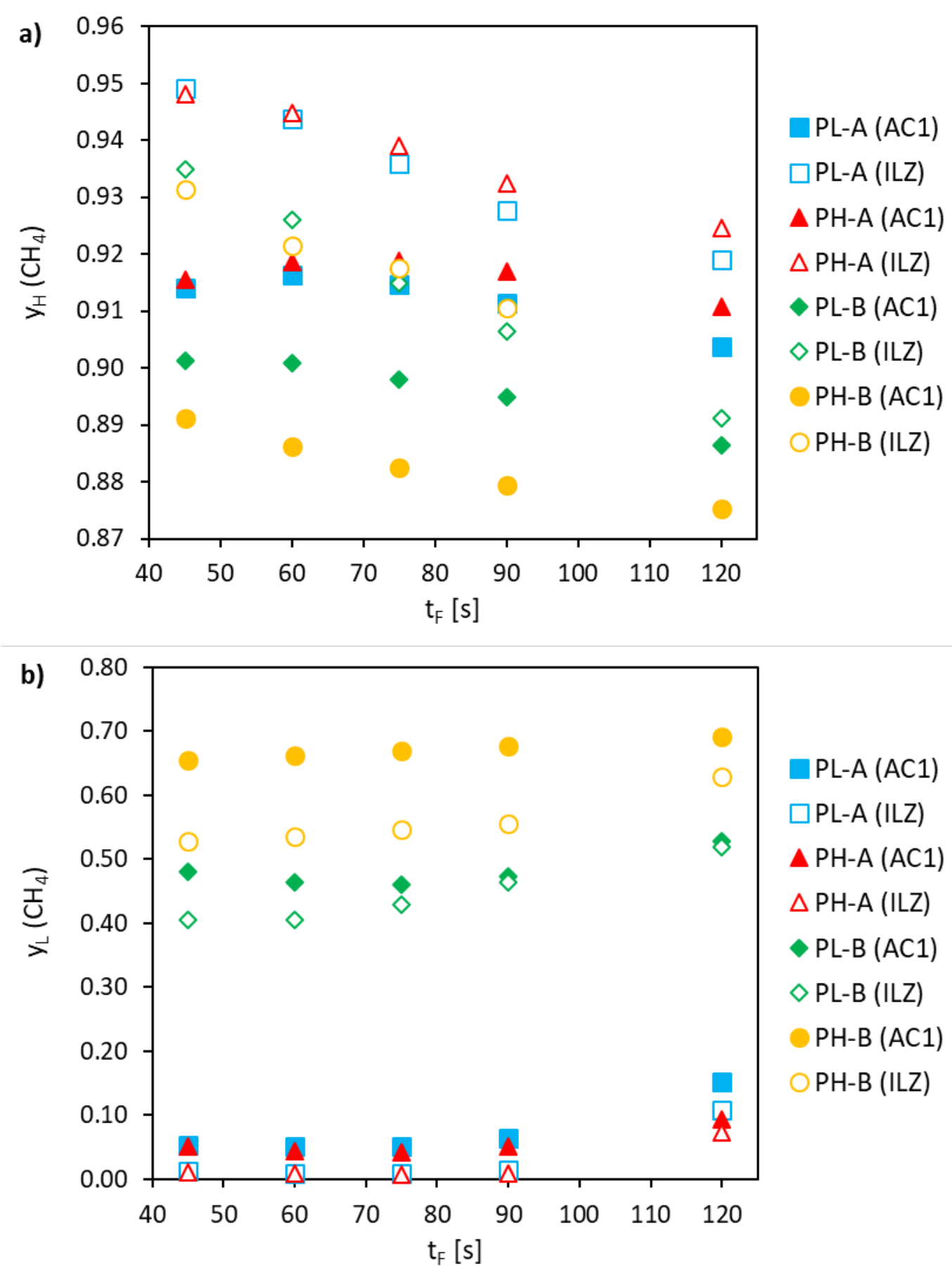

Figure 6. Influence of feed time $t_{F}$ on the a) heavy $\left(y_{H}\right)$ and b) light $\left(y_{L}\right)$ product composition at constant light reflux flow rate $R_{L}=1.5 \mathrm{SLPM}, H / F=0.91$ and 0.88 for AC1 (full symbols) and ILZ (hollow symbols), respectively.

The bed productivity $Z_{p}$ is an important parameter when evaluating the capital costs of a process as it is related to the number of beds required:

$$
Z_{p}=\frac{y_{H} \cdot H_{P} \cdot t_{F}}{\left(t_{P}+t_{F}\right) \cdot m_{a d s}}
$$

Equation 11 
Here $H_{p}$ denotes the heavy product flow rate, $t_{p}$ the time for the pressure transfer step and $m_{\text {ads }}$ the mass of the adsorbent.

Figure 7 shows the bed productivity versus feed time with other process variables held constant for all cycles. It ranges from 2.5 to $4.0 \mathrm{~mol} \mathrm{~kg}^{-1} \mathrm{~h}^{-1}$ for AC1 and from 1.5 to $2.5 \mathrm{~mol} \mathrm{~kg}^{-1} \mathrm{~h}^{-1}$ for ILZ. The higher $Z_{p}$ for AC1 during all variations of $t_{F}$ is mainly caused by different values for $m_{a d s}$ in Eq. 11 caused by the different packing densities of AC1 and ILZ. Although $Z_{p}$ increases with longer feed times, the product purities suffer with this increased feed time. For each adsorbent, the four different cycles show very similar bed productivities at the tested feed times. In both adsorbents, B-cycles have slightly lower productivities than the other configurations. The similar productivity of the four cycles for each adsorbent can be explained by the heavy product purity $y_{H}$ values used in Eq. 11. The high content of $\mathrm{CH}_{4}$ in the feed means that all of the cycles achieve similar productivities because all four cycles show similar heavy product compositions ranging from 88 mol\% to 95 $\mathrm{mol} \% \mathrm{CH}_{4}$.

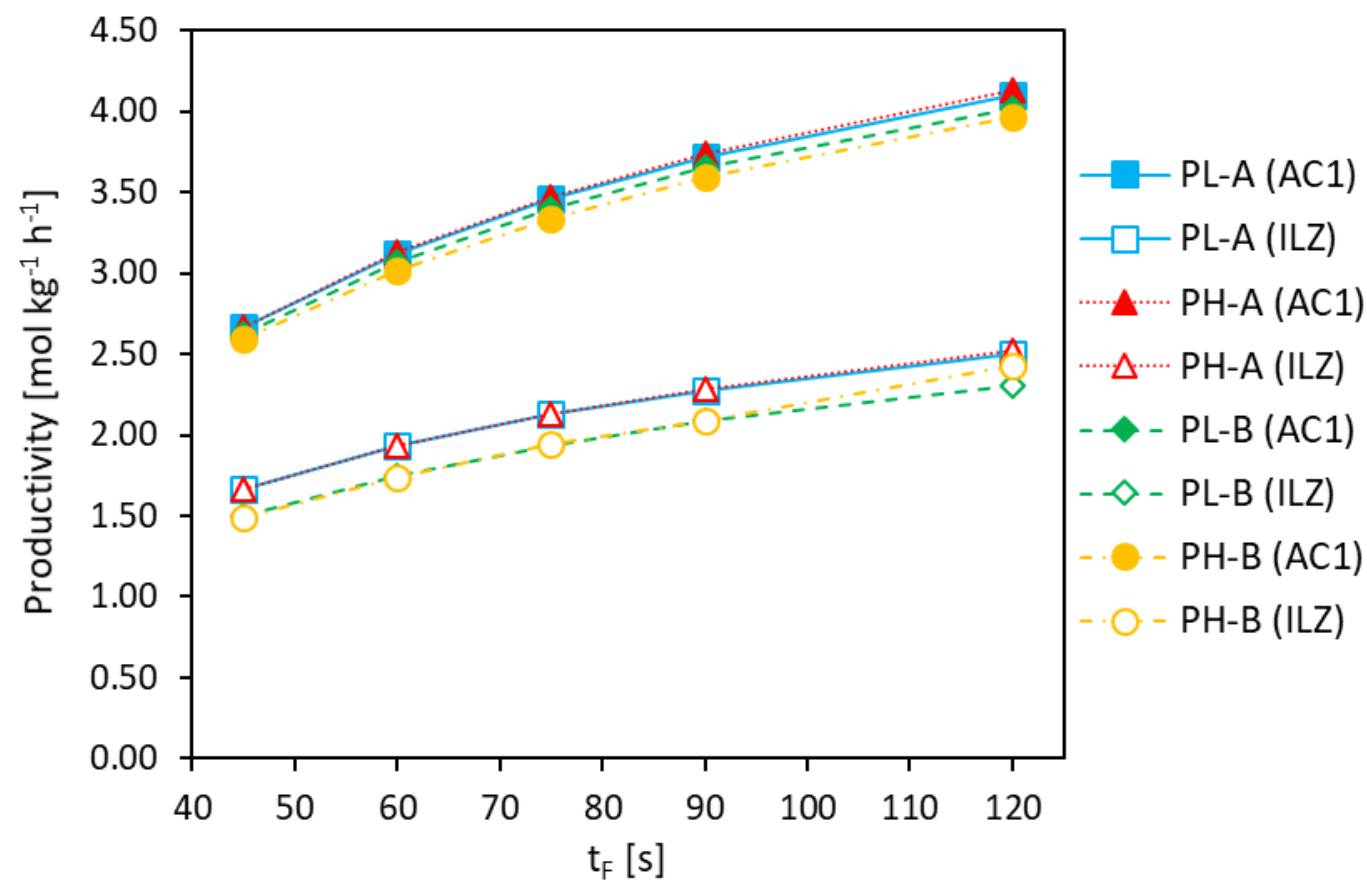

Figure 7. Productivity $Z_{p}$ versus feed step time $t_{F}$ at constant light reflux $R_{L}=1.5 \mathrm{SLPM}$ and $H / F=0.91$ and 0.88 for AC1 (full symbols) and ILZ (hollow symbols), respectively.

\subsection{Capacity Ratio Analysis and Cycle Work}

While the $H / F$ ratio and feed step time allow the separation performance to be shifted either towards increased heavy or light product purity, it does not provide any information about the usage of the bed, and what gains may be achieved through the use of reflux. Therefore, the bed capacity ratio $\mathbb{C}$ is introduced. May et al. [8] proposed an advanced definition that takes several important process parameters such as feed time, feed location and heavy reflux into account. The capacity ratio $\mathbb{C}$ describes the utilization of the adsorbent bed during the feed/purge step and is defined as shown in Equation 12. 


$$
\mathbb{C}=\frac{y_{H} \cdot R_{H} \cdot t_{F}}{n_{A}^{g a s}+n_{A}^{a d s}}+\frac{y_{F} \cdot F \cdot t_{F}}{\left(n_{A}^{g a s}+n_{A}^{a d s}\right)\left(1-Z_{F}\right)}
$$

with

$$
\begin{aligned}
& n_{A}^{g a s}=\left(y_{H}-y_{H}^{\prime}\right)\left(\frac{P_{H} V_{b e d} \varepsilon}{R T}\right) \\
& n_{A}^{a d s}=m_{a d s}\left(Q_{A}-Q_{A}^{\prime}\right)
\end{aligned}
$$

Here $y_{H}$ and $y_{F}$ denote the heavy component composition in the heavy product and feed, respectively, $R_{H}$ denotes the heavy reflux flow, $t_{F}$ the feed time, $F$ the feed flow, $z_{F}$ the axial feed location, $P_{H}$ the high pressure, $V_{\text {bed }}$ the bed's volume, $\varepsilon$ the bed void, $R$ the ideal gas constant, $T$ the bed temperature, $m_{\text {ads }}$ the mass of the adsorbent, and $Q_{A}$ the adsorbent capacity.

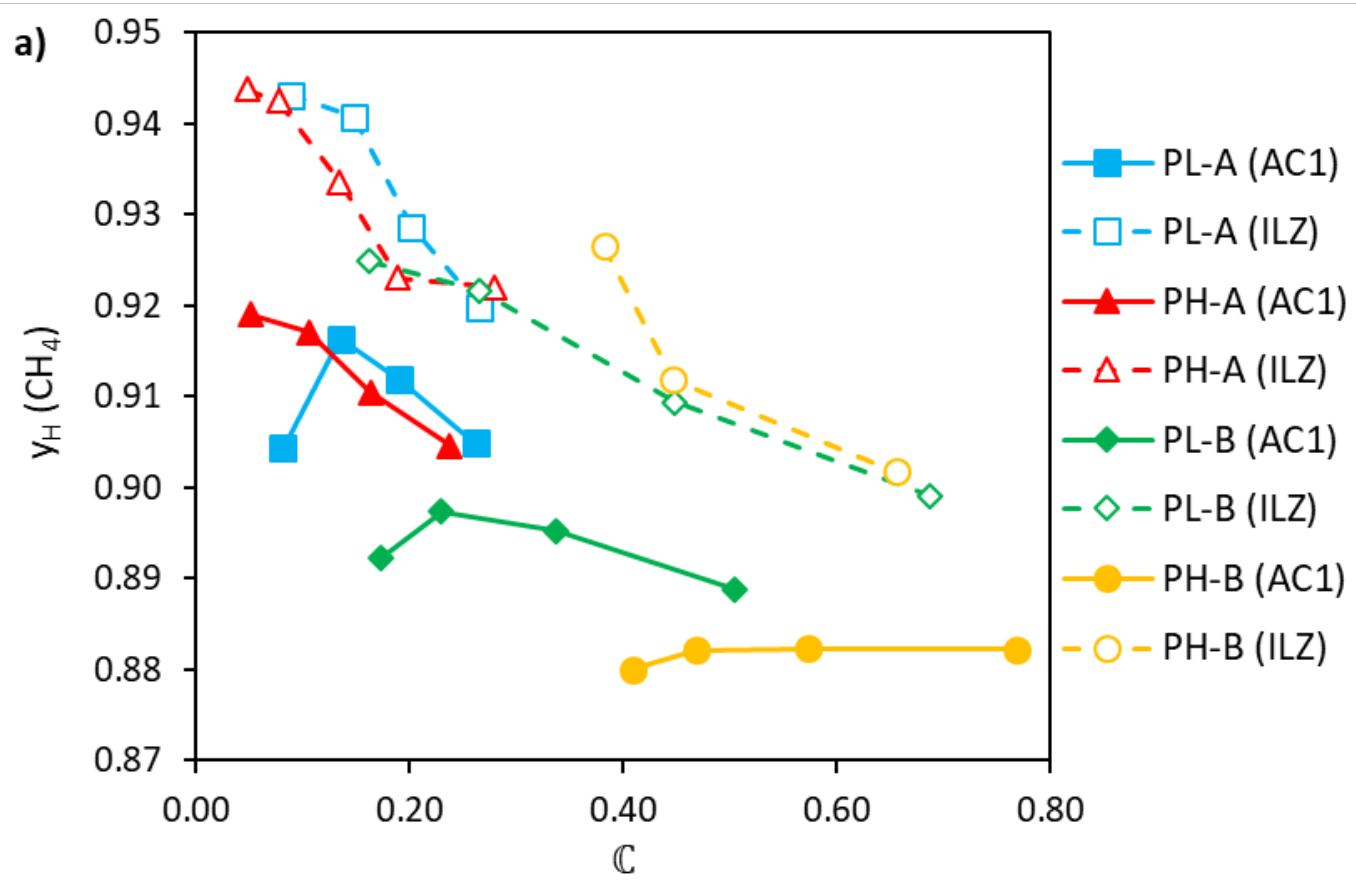




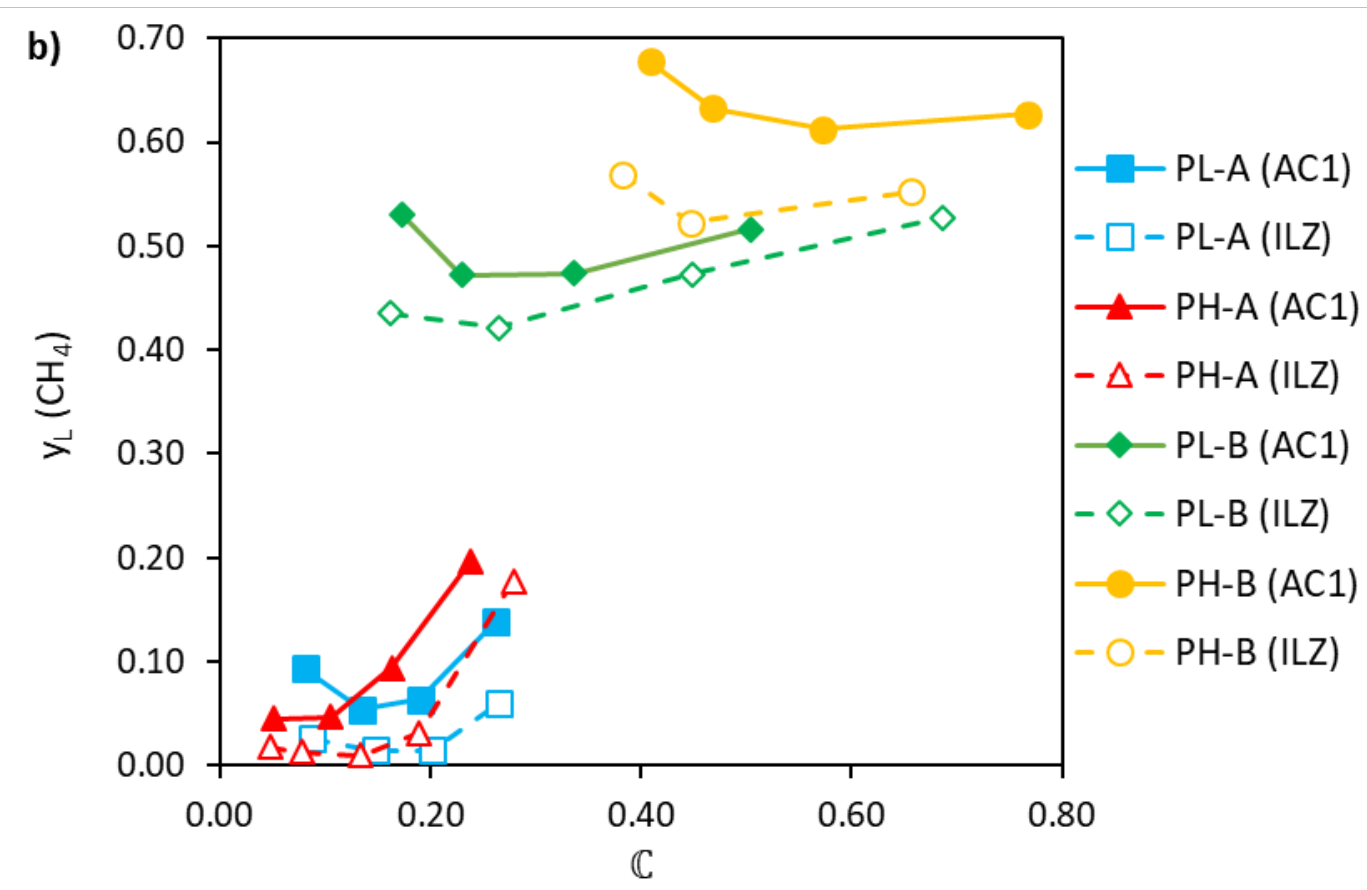

Figure 8. The influence of bed capacity ratio, $\mathbb{C}$, on a) heavy $\left(y_{H}\right)$ and b) light product $\left(y_{L}\right) \mathrm{CH}_{4}$ fraction using adsorbents AC1 (full symbols) and ILZ (hollow symbols), achieved by varying $R_{L}$ from 0.5 SLPM to 3.0 SLPM (with $t_{F}=90 \mathrm{~s}, H / F=0.91$ and 0.88 for AC1 and ILZ, respectively).

Figure 8a shows the bed capacity ratio $\mathbb{C}$ and the corresponding heavy product composition $y_{H}$ for all cycles using both adsorbents. The capacity ratio $\mathbb{C}$ was varied by increasing the light reflux $R_{L}$ from 0.5 SLPM up to 3.0 SLPM (2.4 times of the feed flow). For AC1, PH-A cycles achieve the highest heavy product purity of 92 mol\% $\mathrm{CH}_{4}$, but at a very low $\mathbb{C}$ of 0.05 . The low value of $\mathbb{C}$ implies that only a small section of the bed is actually used for separation. This also applies to the PL-A cycle which achieves a maximum purity of $91.5 \mathrm{~mol} \% \mathrm{CH}_{4}$ at $\mathbb{C}=$ 0.14. In contrast, B-cycles make greater use of the bed, but their separation performance is lower with a maximum of 90 mol\% $\mathrm{CH}_{4}$ in the heavy product. With ILZ as the adsorbent, all cycles achieve higher $\mathrm{CH}_{4}$ concentration in the heavy product. Analogous to AC1, A-cycles perform better reaching $94.4 \mathrm{~mol} \% \mathrm{CH}_{4}$ at $\mathbb{C}$ $=0.05$ for PH-A cycles while PL-A cycles perform similarly achieving $94.3 \mathrm{~mol}^{2} \mathrm{CH}_{4}$ at $\mathbb{C}=0.09$. The Bconfigurations reach 92.6 mol\% $\mathrm{CH}_{4}$ in the heavy product making higher use of the bed. However, their performance in terms of the light product purity is poor. The dependence of $\mathrm{CH}_{4}$ content in the light product $y_{L}$ as a function of the bed capacity ratio is shown in Figure $8 \mathrm{~b}$. The A-cycles achieve the lowest light product $\mathrm{CH}_{4}$ mole fractions with approximately 5 mol\% for PH-A and PL-A cycle, respectively. Both minima are located at the same bed capacity ratio as for the heavy product. The PL-B cycles show a clear minimum of 47 mol\% $\mathrm{CH}_{4}$ at a bed capacity ratio of 0.25 , while the PH-B cycles cannot get below $61 \mathrm{~mol} \% \mathrm{CH}_{4}$ in the light product. No variation of the light reflux was able to improve the separation performance of the B-cycles sufficiently to achieve the desired separation target. This was also found for B-cycles that used ILZ, which produce similar trends to AC1 but with an achievable light product $\mathrm{CH}_{4}$ fraction shifted towards lower $y_{L}$. The light product purity is improved by 5 mol\% and 10 mol\% for PL-B and PH-B, respectively for the ILZ material. The best 
stripping performance is achieved for the PH-A cycles with ILZ, with the minimum $\mathrm{CH}_{4}$ fraction being 1 mol\% at $\mathbb{C}=0.13$. The $\mathrm{PL}-\mathrm{A}$ cycles reach $1.4 \mathrm{~mol} \% \mathrm{CH}_{4}$ in the light product at a bed capacity ratio 0.15 .

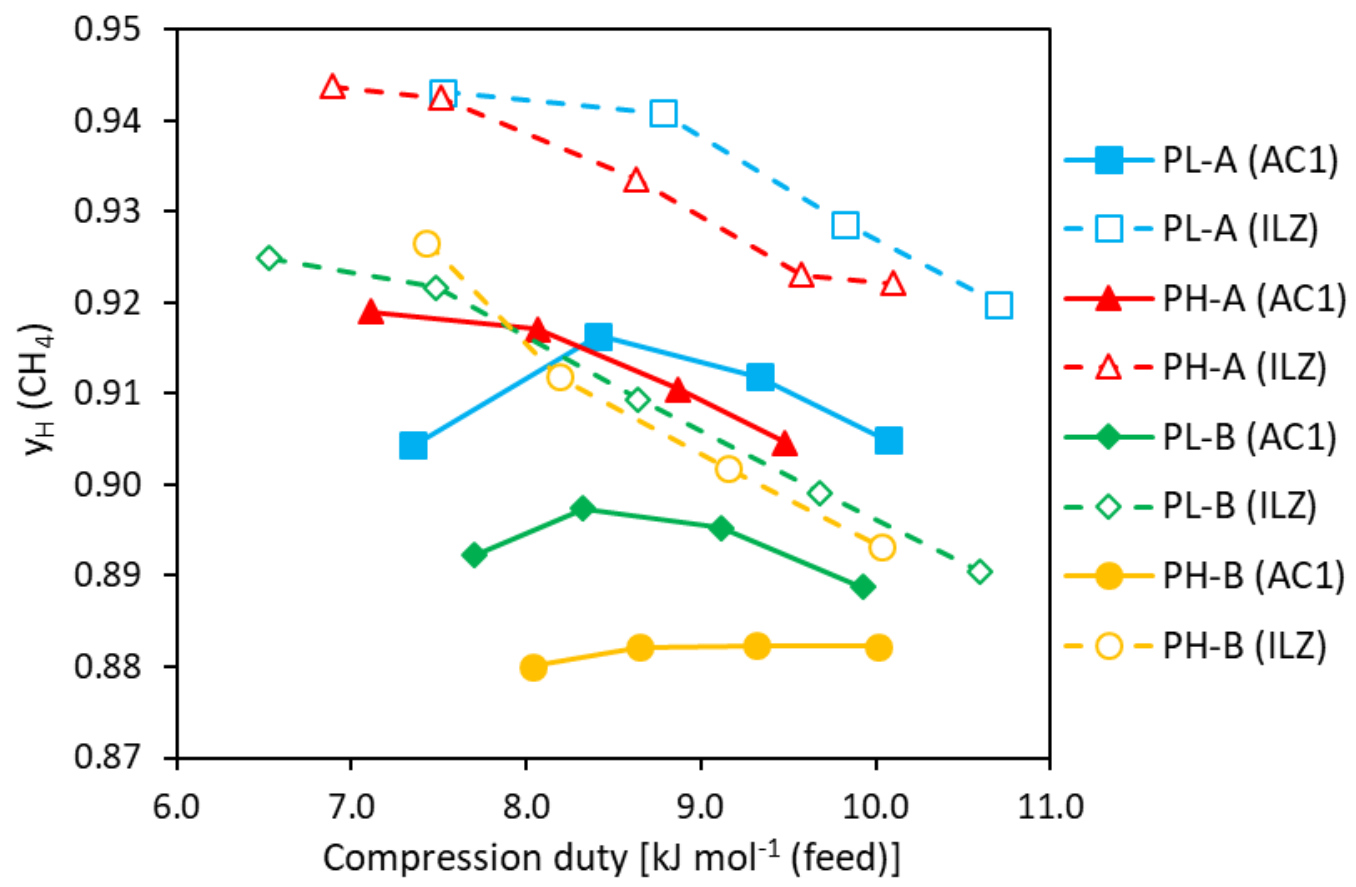

Figure 9. Heavy product composition $y_{H}$ vs polytropic compression duty caused by varying $R_{L}$ from 0.5 to 3.0 SLPM (with $t_{F}=90 \mathrm{~s}, H / F=0.91$ and 0.88 for AC1 (full symbols) and ILZ (hollow symbols), respectively).

The $\mathrm{CH}_{4}$ fraction in the heavy product is plotted against the average cycle duty in Figure 9 . The duty is increased by increasing the light reflux flow $R_{L}$, which will also increase the heavy reflux rate. More material is recycled and remains in the system. Therefore, the power consumed by the compressor increases. However, more power does not necessarily mean that the separation performance improves, as evident from the maxima in $\mathbb{C}$ discussed above. Figure 9 shows that there are maxima in the heavy product $\mathrm{CH}_{4}$ fraction. For $\mathrm{AC} 1, \mathrm{PH}-\mathrm{A}$ cycles achieved the highest $\mathrm{CH}_{4}$ fraction of $91.9 \mathrm{~mol} \%$ at the lowest compressor duty of $7.1 \mathrm{~kJ} \mathrm{~mol}^{-1}$ (per cycle) while PL-A cycles achieve $91.7 \mathrm{~mol} \%$ but required $8.5 \mathrm{~kJ} \mathrm{~mol}^{-1}$. Using ILZ as the adsorbent, the separation performance of PH-A is improved to $94.4 \mathrm{~mol}^{2} \mathrm{CH}_{4}$ with only $6.9 \mathrm{~kJ} \mathrm{~mol}^{-1}$ required. The PL-A cycle with ILZ also performs well achieving $94.3 \mathrm{~mol} \% \mathrm{CH}_{4}$ but at slightly higher power consumption $\left(7.5 \mathrm{~kJ} \mathrm{~mol}^{-1}\right)$ due to the low pressure of the feed gas. Both B-configurations show higher $y_{H}$ values at lower power consumptions using the ILZ instead of AC1. The PH-B cycles do not show a clear maximum and for AC1, it appears that the performance is not improved by higher reflux rates. The PL-B cycles requires $9.1 \mathrm{~kJ} \mathrm{~mol}^{-1}$ for $89.5 \mathrm{~mol}^{\circ} \mathrm{CH}_{4}$ and $6.5 \mathrm{~kJ} \mathrm{~mol}^{-}$ ${ }^{1}$ for $92.5 \mathrm{~mol}^{2} \mathrm{CH}_{4}$ in the heavy product for $\mathrm{ACl}$ and ILZ, respectively. This further emphasizes the superior performance of the ILZ material compared to AC1, not only in terms of separation performance but also in terms of power requirements.

\subsection{Optimization Results}

The optimized operational parameters, the maximum achievable product purities and the corresponding power consumption for all cycle configurations using adsorbents AC1 and ILZ, are summarized in Table 6. 
Cycles using activated carbon AC1 as the adsorbent do not achieve the desired product purities of $<1$ mol\% $\mathrm{CH}_{4}$ in the light and $93 \mathrm{~mol} \% \mathrm{CH}_{4}$ in the heavy product. The PL-A and PH-A cycles achieve very similar results at optimized conditions with approximately $92 \mathrm{~mol} \% \mathrm{CH}_{4}$ in the heavy product and $4.5 \mathrm{~mol} \% \mathrm{CH}_{4}$ in the light product. However, the PH-A cycle's separation performance is slightly superior and it requires less work per cycle: while the PL-A cycle requires $9.9 \mathrm{~kJ} \mathrm{~mol}^{-1}$, the $\mathrm{PH}-\mathrm{A}$ cycle only needs $8.7 \mathrm{~kJ} \mathrm{~mol}^{-1}$. This is also reflected with the B-cycles because the feed is already at high pressure (as stated by May et al. [8]). The B-cycles need more cycle work due to the increased light reflux rate and lower feed time. This compounds upon the disadvantages of having to use two compressors and the comparatively poor separation performance. For cycles using ILZ as the adsorbent, the product purity targets are met with A-configurations achieving $<1$ mol\% $\mathrm{CH}_{4}$ in the light product and $>93 \mathrm{~mol} \% \mathrm{CH}_{4}$ in the heavy product. In addition, the power requirements are lower than for AC1 because of the lower light reflux flow rates. The cycle work of the PL-A and PH-A cycles is 8.8 and $7.7 \mathrm{~kJ} \mathrm{~mol}^{-1}$ (feed), respectively. Similar to AC1, the B-cycles performed poorly compared to the Acycles.

Table 6. Optimized parameters and results for AC1 and ILZ.

\begin{tabular}{|l|c|c|c|c|c|c|c|}
\hline & $H / F$ & $R_{L}[\mathrm{SLPM}]$ & $t_{F}[\mathrm{~s}]$ & $y_{H}\left(\mathrm{CH}_{4}\right)$ & $y_{L}\left(\mathrm{CH}_{4}\right)$ & $W\left[\mathrm{~kJ} \mathrm{~mol}^{-1}(\mathrm{feed})\right]$ & $Z_{p}\left[\mathrm{~mol} \mathrm{~h}^{-1} \mathrm{~kg}^{-1}\right]$ \\
\hline \multicolumn{8}{|c|}{ AC1 } \\
\hline PL-A & 0.91 & 1.5 & 60 & 0.916 & 0.048 & 9.9 & 3.12 \\
\hline PH-A & 0.91 & 1.5 & 65 & 0.919 & 0.043 & 8.7 & 3.25 \\
\hline PL-B & 0.91 & 2.0 & 50 & 0.901 & 0.457 & 10.7 & 2.79 \\
\hline PH-B & 0.91 & 4.0 & 35 & 0.898 & 0.537 & 12.5 & 2.25 \\
\hline \multicolumn{7}{|c|}{ ILZ } \\
\hline PL-A & 0.90 & 1.0 & 90 & 0.934 & 0.009 & 8.8 & 2.29 \\
\hline PH-A & 0.90 & 1.0 & 90 & 0.935 & 0.009 & 7.7 & 2.29 \\
\hline PL-B & 0.91 & 2.0 & 30 & 0.930 & 0.385 & 9.5 & 1.14 \\
\hline PH-B & 0.91 & 3.0 & 35 & 0.932 & 0.440 & 10.1 & 1.27 \\
\hline
\end{tabular}

Figure 10 highlights the achievable performance at optimized conditions of both adsorbents. The PH-A configuration was found to be slightly superior to PL-A, whereas B-cycles were not competitive at all. Overall, for the conditions considered here, using ILZ as the adsorbent delivers significantly improved performance compared to $\mathrm{AC} 1$ in terms of product purities, $\mathrm{CH}_{4}$ recovery and power consumption. Higher bulk density and increased selectivity are the main advantages of the ILZ. 


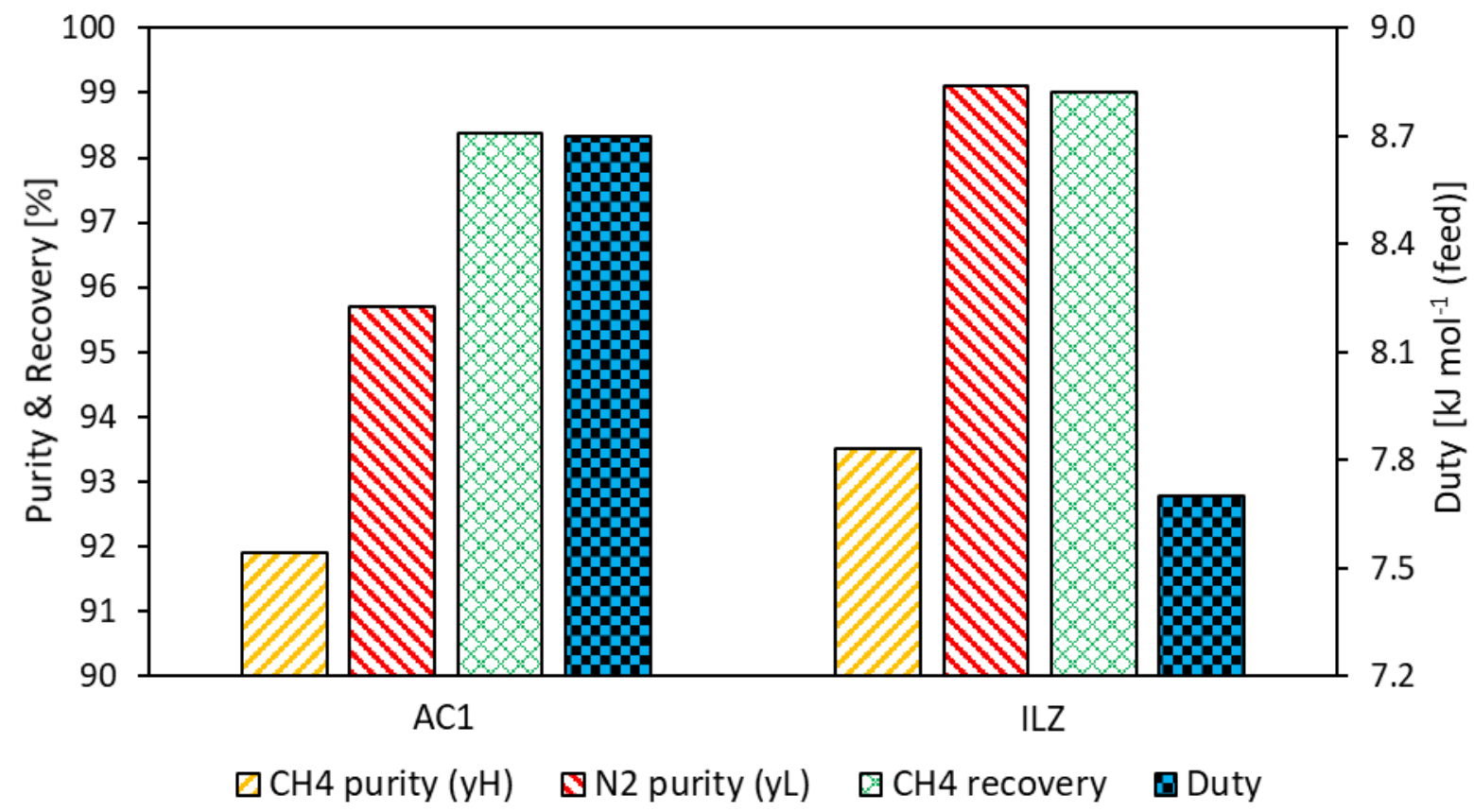

Figure 10. Comparison of optimized separation performance and cycle work for AC1 and ILZ, both achieved by $\mathrm{PH}-\mathrm{A}$ configuration.

\section{Conclusions}

The separation of an 85 mol\% $\mathrm{CH}_{4}$ and 15 mol\% $\mathrm{N}_{2}$ gas mixture was numerically studied using a DR PSA model constructed on the Aspen Adsorption platform. The PL-A, PH-A, PL-B and PH-B cycle configurations were investigated with two different adsorbents: commercially available activated carbon $\mathrm{AC} 1$ and the recently developed ionic liquidic zeolite. The effect of $H / F$ ratio, feed step time $t_{F}$, and light reflux flow $R_{L}$ was studied for the aforementioned cycle configurations and optimized values of these parameters were identified for each configuration using an iterative optimization approach. The productivity and compressor duties were obtained for each of the optimized conditions. For both adsorbents, the A-configurations were clearly superior compared to the B-configurations in terms of separation performance. The ILZ achieved the highest $\mathrm{N}_{2}$ product purity and $\mathrm{CH}_{4}$ recovery at the lowest cycle work. The optimized PH-A cycle with ILZ was able to deliver 93.5 mol\% $\mathrm{CH}_{4}$ in the heavy product $\left(99 \% \mathrm{CH}_{4}\right.$ recovery) and $0.9 \mathrm{~mol} \% \mathrm{CH}_{4}$ in the light product with a compressor duty of $7.7 \mathrm{~kJ} \mathrm{~mol}^{-1}$ (feed). The optimized PH-A cycle using AC1 was only capable of achieving $91.9 \mathrm{~mol} \% \mathrm{CH}_{4}$ in the heavy product and $98 \% \mathrm{CH}_{4}$ recovery $\left(4.3 \% \mathrm{CH}_{4}\right.$ in the light product), consuming $8.7 \mathrm{~kJ} \mathrm{~mol}^{-1}$ (feed). Only the optimized PH-A cycle using the ILZ adsorbent is able to meet the specified separation target. Up to $70 \%$ of the cycle duty was associated with the pressurisation and blowdown steps, which would be common to a conventional PSA process with poorer separation performance. Thus using DR PSA cycles to achieve the stated separation targets only requires 2 to $3 \mathrm{~kJ} \mathrm{~mol}^{-1}$ (feed) of additional cycle duty. 


\section{Acknowledgements}

This research was supported by the ARC Training Centre for LNG Futures (IC150100019). RW was in receipt of an Australian Government Research Training Program Scholarship at The University of Western Australia during this research.

\section{References}

[1] BP statistical review of world energy June 2018, in, 2018.

[2] T.E. Rufford, S. Smart, G.C.Y. Watson, B.F. Graham, J. Boxall, J.C.D. da Costa, E.F. May, The removal of $\mathrm{CO}_{2}$ and $\mathrm{N}_{2}$ from natural gas: A review of conventional and emerging process technologies, J Petrol Sci Eng, 94-95 (2012) 123-154.

[3] G.M. Crawley, The world scientific handbook of energy, World Scientific Publishing Co. Pte. Ltd., 2013.

[4] J.C. Kuo, K.H. Wang, C. Chen, Pros and cons of different Nitrogen Removal Unit (NRU) technology, J Nat Gas Sci Eng, 7 (2012) 52-59.

[5] A.J. Kidnay, W.R. Parrish, D.G. McCartney, Fundamentals of natural gas processing, 2nd ed., CRC Press, 2006.

[6] S. Mokhatab, W.A. Poe, J.G. Speight, Handbook of natural gas transmission and processing, Elsevier Science, 2017.

[7] A. Finn, Rejection strategies, Hydrocarbon Engineering, 12 (2007) 49-52.

[8] E.F. May, Y. Zhang, T.L.H. Saleman, G. Xiao, G. Li, B.R. Young, Demonstration and optimisation of the four dual-reflux pressure swing adsorption configurations, Separation and Purification Technology, 177 (2017) 161-175.

[9] D. Diagne, M. Goto, T. Hirose, New PSA process with intermediate feed inlet position operated with dual refluxes: application to carbon dioxide removal and enrichment, Journal of chemical engineering of Japan, 27 (1994) 85-89.

[10] D. Diagne, M. Goto, T. Hirose, Experimental-study of simultaneous removal and concentration of $\mathrm{CO}_{2}$ by an improved pressure swing adsorption process, Energ Convers Manage, 36 (1995) 431-434.

[11] D.T. Kearns, P.A. Webley, Modelling and evaluation of dual-reflux pressure swing adsorption cycles: Part I. Mathematical models, Chem Eng Sci, 61 (2006) 7223-7233.

[12] T.S. Bhatt, G. Storti, J.F.M. Denayer, R. Rota, Optimal design of dual-reflux pressure swing adsorption units via equilibrium theory: process configurations employing heavy gas for pressure swing, Chem Eng J, 311 (2017) 385-406.

[13] T.S. Bhatt, G. Storti, J.F.M. Denayer, R. Rota, Equilibrium theory-based assessment of dual-reflux pressure swing adsorption cycles that utilize light gas for pressure swing, Ind Eng Chem Res, 58 (2019) 350365.

[14] T.S. Bhatt, G. Storti, R. Rota, Optimal design of dual-reflux pressure swing adsorption units via equilibrium theory, Chem Eng Sci, 102 (2013) 42-55.

[15] A.D. Ebner, J.A. Ritter, Equilibrium theory analysis of rectifying PSA for heavy component production, Aiche J, 48 (2002) 1679-1691.

[16] A.D. Ebner, J.A. Ritter, Equilibrium theory analysis of dual reflux PSA for separation of a binary mixture, Aiche J, 50 (2004) 2418-2429.

[17] D.T. Kearns, P.A. Webley, Modelling and evaluation of dual reflux pressure swing adsorption cycles: Part II. Productivity and energy consumption, Chem Eng Sci, 61 (2006) 7234-7239.

[18] T.S. Bhatt, A. Sliepcevich, G. Storti, R. Rota, Experimental and modeling analysis of dual-reflux pressure swing adsorption process, Ind Eng Chem Res, 53 (2014) 13448-13458.

[19] T.S. Bhatt, G. Storti, R. Rota, Detailed simulation of dual-reflux pressure swing adsorption process, Chem Eng Sci, 122 (2015) 34-52.

[20] J.A. Mc Intyre, C.E. Holland, J.A. Ritter, High enrichment and recovery of dilute hydrocarbons by dualreflux pressure-swing adsorption, Industrial \& Engineering Chemistry Research, 41 (2002) 3499-3504. 
[21] J.A. McIntyre, A.D. Ebner, J.A. Ritter, Experimental study of a dual reflux enriching pressure swing adsorption process for concentrating dilute feed streams, Ind Eng Chem Res, 49 (2010) 1848-1858.

[22] Y. Zhang, T.L.H. Saleman, G. Li, G. Xiao, B.R. Young, E.F. May, Non-isothermal numerical simulations of dual reflux pressure swing adsorption cycles for separating $\mathrm{N}_{2}+\mathrm{CH}_{4}$, Chemical Engineering Journal, 292 (2016) 366-381.

[23] Y.C. Zhang, T.L.H. Saleman, G. Li, G.K. Xiao, B.R. Young, E.F. May, Non-isothermal numerical simulations of dual reflux pressure swing adsorption cycles for separating $\mathrm{N}_{2}+\mathrm{CH}_{4}$, Chem Eng J, 292 (2016) 366-381. [24] T.L. Saleman, G. Li, T.E. Rufford, P.L. Stanwix, K.I. Chan, S.H. Huang, E.F. May, Capture of low grade methane from nitrogen gas using dual-reflux pressure swing adsorption, Chem Eng J, 281 (2015) 739-748. [25] Y. Zou, G.K. Xiao, G. Li, W. Lu, E.F. May, Advanced non-isothermal dynamic simulations of dual reflux pressure swing adsorption cycles, Chem Eng Res Des, 126 (2017) 76-88.

[26] G. Xiao, T.L. Saleman, Y. Zou, G. Li, E.F. May, Nitrogen rejection from methane using dual-reflux pressure swing adsorption with a kinetically-selective adsorbent, Chemical Engineering Journal, 372 (2019) 10381046.

[27] T.E. Rufford, G.C.Y. Watson, T.L. Saleman, P.S. Hofman, N.K. Jensen, E.F. May, Adsorption Equilibria and Kinetics of Methane plus Nitrogen Mixtures on the Activated Carbon Norit RB3, Ind Eng Chem Res, 52 (2013) 14270-14281.

[28] Gas Capture Technologies Pty Ltd, Innovative gas capture \& recovery technology, in, http://gascapture.com.au/, 2019.

[29] R.M. Felder, R.W. Rousseau, Elementary principles of chemical processes, 3rd Edition, John Wiley \& Sons, 2004. 